\title{
Paisaje, identidad y nación en el Caribe poscolonial: Edouard Glissant y Derek Walcott*
}

Fecha de recepción: 14 de agosto de 2017

Fecha de aceptación: 20 de septiembre de 2017

\section{Resumen}

El rol del paisaje es cardinal en el discurso caribeño: supera su categoría de décor consentant y emerge como una enérgeia que impulsa al hombre a sumergirse dentro de él y re-conocerse. Luego de la erosión identitaria que marcó la travesía atlántica, la escisión entre sujeto y lugar que representó la ruta media y las instancias de negociación en la grieta que instaló su adaptación al Nuevo Mun-do, el sujeto cultural poscolonial del Caribe desarrolla una identidad transnacional, atada a su paisaje atravesado de horizontes, en un contrabando perpetuo de lenguas, etnias y fronteras, con la certeza de pertenecer a un mundo nuevo, que construye sus naciones más allá de los monumentos y documentos heredados del imperio. El Caribe emerge en una ola rebelde que se vuelca en nuevas playas de la memoria. Las poéticas del Caribe construyen la nación desde la imaginación, como lo formula Derek Walcott. Por su parte, Edouard Glissant habla de une poétique de la relation en el Caribe, poética de la exuberancia y del éxtasis, salida poética para el náufrago. El análisis de estos inéditos imaginarios nos llevará desde los estudios literarios, hacia la antropología, la etnografía y los estudios interdisciplinarios de la cultura.

Palabras clave: Paisaje, Caribe, identidad, transnacional, poscolonial, Walcott, Glissant, poética.

Citar: Maglia, G. (julio-diciembre de 2017). Paisaje, identidad y nación en el Caribe poscolonial: Edouard Glissant y Derek Walcott. La Palabra, (31), 89-99. doi: https://doi.org/10.19053/01218530.n31.2017.7283.

\section{Graciela Maglia}

Profesora Instituto Caro y Cuervo. Doctora en Literatura, Sorbona, París IV. Fulbright Scholar in Residence. DEAUniversité Paul Valéry de Montpellier. gracielamaglia@gmail.com

* Artículo de investigación. 


\section{Landscape, Identity and Nation in the Postcolonial Caribbean: Edouard Glissant and Derek Walcott}

The role of landscape is central in Caribbean discourse; it overcomes the category of décor consentant and emerges as an enérgeia that propels man into himself and into his self-recognition. After the erosion of identity caused by the Atlantic crossing, the scission between subject and place caused by the middle passage and the negotiation of an in-between space adapted to the New World, the Caribbean postcolo-nial cultural subject develops a transnational identity. An identity attached to the landscape and scenery, crossed by horizons, in a perpetual contraband of tongues, ethnic groups and borders. This identity has the certainty of belonging to a New World, which is constructs its nations beyond the monuments and documents inherited from the Empire. The Caribbean emerges as a rebellious wave that spills its water on new beaches of memory. The poetics of the Caribbean build Nation from the imagination, as Derek Walcott proposes. On the other hand, Edouard Glissant speaks about une poétique de la relation in the Caribbean, a poetic of exuberance and ecstasies, a poetical outcome for the shipwrecked. The analysis of these unprecedented imaginaries will take us from Literary Studies to Anthropology, Ethnography and Cultural Studies.

Key words: Landscape, Caribbean, identity, transnational, postcolonial, Walcott, Glissant, poetics.

\section{Paysage, identité et nation dans les Caraïbes postcoloniaux: Edouard Glissant et Derek Walcott}

\section{Résumé}

Le rôle central du paysage dans le discours caribéen dépasse sa catégorie de décor consentant et surgit comme enérgeia qui pousse l'homme à se plonger à l'intérieur de lui-même et à se re-connaître. L'érosion identitaire produite par la traversée de l'atlantique et la rupture entre le sujet et le lieu représenté par la traite atlantique orientent le sujet postcolonial caribéen vers le développement d'une identité transnationale, liée au paysage, dans une contrebande perpétuelle de langues, ethnies et frontières, avec la certitude d'appartenir à un nouveau monde qui construit ses nations au-delà des monuments et des documents hérités de l'empire. Les Caraïbes apparaissent comme une vague rebelle qui va vers les nouvelles plages de la mémoire. Les poétiques des caraïbes construisent leur conception de nation à partir de l'imagination, comme l'affirme Derek Walkott. De son côté, Edouard Glissant propose une poétique de la relation aux Caraïbes, de l'exubérance et de l'extase, comme renouvellement poétique des visions 
traditionnelles. Nous proposerons une analyse de ses textes imaginaires inédits à partir des études littéraires, en passant par l'anthropologie et l'ethnographie en allant jusqu'aux études interdisciplinaires de la culture.

Mots-clés: paysage, identité, transnational, postcolonial, Walcott, Glissant, poé

\section{Introducción}

El rol del paisaje es cardinal en el discurso caribeño: supera su categoría de décor consentant, de entorno balsámico y emerge como una enérgeia que impulsa al hombre a sumergirse dentro de él y re-conocerse. El homo caribbeans experimenta su paisaje como un pathos: de la tierra fue enajenado durante la trata negrera, en relación con la tierra fue explotado, tanto en las plantaciones como en las mi-nas de oro y plata y, privado de ella, fue esclavizado. Luego de la erosión identitaria que mar-có la travesía atlántica (Gilroy, 1992), la escisión entre sujeto y lugar (Ashcroft et al., 1989) que representó la ruta media ${ }_{1}$ y las instancias de negocia-ción en la grieta que instaló su adaptación al Nuevo Mundo, el sujeto cultural poscolonial2 del caribe desarrolla una identidad transnacional, atada a su paisaje atravesado de horizontes, en un contrabando perpetuo de lenguas, etnias y fronteras, por una parte; pero, por otra, con la certeza de pertenecer a un mundo nuevo, que construye sus naciones más allá de los monumen- tos $\mathrm{y}$ documentos heredados del imperio.

Resistente a las definiciones coloniales, el caribe emerge en una ola rebelde que se vuelca en nuevas playas de la memo-ria. Lejos de las definiciones duduistas del discurso hegemónico y de la visión estereotipa-da de un caribe "para el ojo del turista", las poéticas del caribe construyen la nación desde la imaginación, como lo formula Derek Walkott (1996). Por su parte, Edouard Glissant (1997) habla de une poétique de la relation en el caribe, poética de la exuberancia y del éxtasis, salida poética para el náufrago. El Caribe se expresa a través de un arte crudo, sin pulir, que no se rinde a la subjetividad del autor, sino que expresa las pulsiones del inconsciente colectivo, en su flujo anómico, con la oscura carnalidad verbal del Caribe.

La incapacidad del colonizador europeo de concebir al Otro desde fuera de las instancias del propio sistema, se traduce en una serie de mitos sobre el Nue-vo Mundo; unos son eufóricos, como el que alude a la dimen- sión edénica de América; otros, disfóricos, como la Leyenda Negra del Caribe antropófago. En todas estas proyecciones, el paisaje del caribe es orientalizado (Said, 1978) desde los ojos imperiales. En su ensayo "La musa de la Historia" (Walcott, 1998), el nobel de Santa Lucía define el Caribe como "un segundo Edén", diferente de los paraísos perdidos de la antigüedad y de las erráticas utopías renacentistas.

La alienación de la visión y crisis de la autoimagen que produce el traslado de África a América en la genealogía del Caribe, se manifiesta principalmente en las construcciones de lugar que caracterizan su discurso. Por esta razón, el análisis de estos inéditos imaginarios nos llevará mucho más allá de los estudios literarios, hacia la antropología, la etnografía y los estudios interdisciplinarios de la cultura, en el camino de la comprensión de los microuniversos semánti-cos que constituyen las macroconstelaciones del sentido en el Caribe poscolonial.

\footnotetext{
Self y place, middle passage.

2 Cf. Montenegro de la Hoz, N. (enero-junio de 2014). Changó, el gran putas: formas de resistencia e identidad esclavizada en los estudios poscoloniales. La Palabra, (24), 59-66
} 
Paisaje, memoria y nación en Derek Walcott:

El paisaje del Caribe como horizonte del migrantes

La poética del paisaje en De-rek Walcott, está estrechamente unida a la dimensión identitaria: el mundo caribeño no solo se define por una metáfora espacial, sino también temporal: leemos en los palimpsestos de The Odyssey (Walcott, 1990) una remisión a la memoria mediterránea que bebe especialmente en la fuente helénica. La Odisea homérica constituye un hipotexto que hablará en Walcott, ya no desde la solemnidad de la supraperspectiva épica que mira al pasado para prestigiar el naciente estado helénico, sino desde una reescritura híbrida, en la que no falta la resemantización léxica, no exenta de efectos humorísticos que subvierten la solemnidad asertiva del mun-do clásico y explotan en nuevo texto algunos elementos que ya anunciaban la modernidad en el modelo griego. Tal es el caso del siguiente pasaje, en el cual Penélope rechaza el asedio del pretendiente Antínoo, con el argumento de su sumisión al orden patriarcal, representado por la voluntad del marido: "Penélope: [...] seguiré sus órdenes. Antíno: Ord-iseo ha estado perdido desde Troya y su deseo vulnerado.”4 (pp. 56-57).

El efecto cómico surge con el juego de palabras según el cual Ord-iseo (y no Odiseo) es el que da las órdenes y Penélope es quien las cumple. Más adelante, durante la Telemaquia -o búsqueda de Odiseo por parte de Telémaco-, Telémaco entrará a las grutas marinas del rey Menelao y llamará a gritos a su padre, para que el eco lleve el reclamo a través de las islas del archipiélago, anhelando llegar al oído paterno.

"Telémaco: ¡Repetid conmigo, islas!. ¡Odi-seo,! Odisea... Eco

Mar, mar, mar...Odisea... Telémaco:

¡Quiero verte, padre! Eco

Más lejos, más lejos, mucho más..."s (pp. 96-98).
En el texto inglés original se puede apreciar cómo, a través de un juego de palabras que explota la asociación fónica, en la voz del Eco se transforma el nombre de Odiseo en onomástica simbólica de la distancia marítima que separa al hijo del padre (Odys-seus, Odysee [to see: ver], sea [mar]. En el diálogo en las cuevas, la voz de Telémaco representa la voz de Homero y el Eco la voz de Walcott. En la obra homérica, la distancia será redimida con el reencuentro de Odiseo y Telémaco y el reestablecimiento del antiguo orden. Pero en la Odisea de Walcott, la distancia será irreparable, como lo expresa la nueva asociación fónica: father [padre], farhter [más lejos], porque en el Caribe no es posible reconciliar al hijo y el padre, como lo expresa el autor en La voz del crepúsculo,

Acepto este archipiélago de las Américas. Al antepasado que me vendió y al antepasado que me compró les digo: no tengo padre, no quiero a ese padre, aunque os entiendo, espíritu negro, espíritu blanco, cuando los dos

\footnotetext{
3 Del gr. tele, machia: (el que) lucha en la distancia.

4 "Penelope:

[...] I'll follow his orders.

Antinous:

Ord-ysseus is lost since Troy, his wish disobeyed."

5 "Telemachus:

Echo me, islands! Odys-seus! Odysee..

Echo:

Sea, Sea, Sea...Odyseeee...

Telemachus:

I want to see you, father!

Echo

Farther, farther ...[...]"
} 
susurrais "historia", pues si intento perdonaros a ambos caigo en esa idea vuestra de la historia que justifica y explica y expía, aunque no soy yo, aunque no soy yo quien ha de perdonar, mi memoria no logra concitar el amor filial, porque vuestros rasgos son anónimos y han sido borrados, y yo no tengo deseo ni fuerza para perdonar. (p. 86).

El Caribe está enfermo de distancias, surcado de regresos6, nutrido de horizontes.7 Odiseo, Ulises, es el ánthropos, el hombre que nace de las cóncavas memorias del mundo arcaico y parte hacia el occidente, más allá del non plus ultra del peñón gibraltareño, arribando a Lisboa, Ulisiboa, y, más lejos aún, hasta las nuevas playas de un Nuevo Mundo en la Odisea caribeña de Walcott.

[...] soy una voz que se retuerce como cien voces con una sola raíz, cue-va hendida de la diosa de donde nacieron en alegre homenaje todas estas escenas y espectáculos, cuyo hijo en este teatro es el cantante con ojos de po- derosa voz, estas piedras rotas donde los rebaños se desplazaban a través de verdes laderas al igual que las grandes olas pastorean sobre el mar desde la sagrada Siracusa hasta las is-las ancladas con palmeras. (p. 373).8

En el Caribe, la relación paisaje/ identidad se inscribe de manera ambivalente: por una parte, la sed de horizonte es una sirena devoradora -Caribe centrífugo-; por otra, la sed de hogar es una lenta Circe que cocina desde las profundas calderas del alma Caribe centrípeto-. En este extremo, Penélope, la roca madre, Ítaca, isla, patria prototípica, morada, fuego del hogar, la nutricia-nodriza Euriclea. El principio femenino, reconfirmado en Homero con el reencuentro Ulises/Penélope y la matanza de los pretendientes, en la Odi-sea de Walcott, en cambio, su-fre un vaciamiento de su valor símbólico. Veamos el siguiente pasaje, en el cual es burlado el principio de autoridad que representa Euriclea, nodriza de Ulises: Antino[...] (a Penélo-pe) ¿¿Has visto de qué mane-ra una criada habla delante de nosotros?. Penélope: Ella es el sostén de esta casa. Ha sido su nodriza. Antino: Pero sus tetas están ahora secas. [...]9 (p. 55).

\section{El paisaje del Caribe como se-gundo Edén}

La poesía de Derek Walcott pone de manifiesto una coincidencia filogenética y ontogenética: el amanecer del mundo es el amanecer del hombre en la historia. En este nuevo comienzo, la palabra poética es adánica: nombra por primera vez dentro de un nuevo ethos, dentro de lo que Bourdieu llamaría el habitus Caribe. Walcott rechaza la poesía de las afro-reclamaciones y lo que él mismo ha denominado el dolor fonético. Las manzanas ácidas de este Segundo Edén en América proporcionan no solo un conocimiento ético, sino un conocimiento histórico, dado que en el Caribe, el bien y el mal han hecho la travesía atlántica. Dice en La voz del crepúsculo:

Para el poeta, el mundo es siempre una mañana. La historia, una noche insomne y olvidada... porque el destino de la poesía es enamorarse del mundo a

En el sentido etimológico, del gr. nostos: regreso y algos: dolor.

7 Del griego horizo: limitar, a su vez de horao, ver.

8 "I am one voice that writhes like a hundred voices with a single root, cleft cave of the goodness from whom all these scenes and spectacles were born in exultant homage, whose son is the aloud-eyed singer of this theatre, these broken stones where flocks moved on green slopes the way breakers graze on the sea in sacral Syracusa as far as the palm-

9 anchored islands." "Antinous

(To Penelope) See how a servant talks in front of us?

Penelope

She is this house's foundation. She was his nurse.

Antinous

Well, her dugs are dry now." 
pesar de la historia. Hay una fuerza exultante, una celebración de la fortuna cuando un escritor se convierte en testigo del amanecer de una cultura que se define a sí misma rama a rama, hoja a hoja por lo que resulta muy oportuno ejecutar el rito de la salida del sol, especialmente a la orilla del mar. (p. 103).

La luz representa un marcador temporal y emocional en el paisaje caribeño: mientras las últimas luminiscencias del atardecer anuncian la vuelta al hogar, el rocío del amanecer constituye la llamada del mundo, la invitación a partir. Y la partida del hogar es siempre épica: el mundo llama a la aventura de vivir. Leemos en La voz del crepúsculo: "Cuando el anochecer realza, como el ámbar en un decorado escénico, esas destartaladas vallas publicitarias de madera y hierro oxidado que cercan nuestras ciudades, una tristeza teatral se desprende de ella, pues el resplandor, como el aura de una vieja lámpara de la- tón, es como una señal de la infancia para regresar a casa."(p. 13).

Y nada más diciente que el triste amanecer con que comienza El reino del caimito, cuando Shabine abandona su isla y su familia:

"En el patio agrisado por el alba,

Permanecí como una piedra y nada más se movía Salvo un mar glacial que ondeaba galvanizado Y las claveras de las estrellas en la bóveda celeste, Hasta que un viento comenzó a inmiscuirse con los árboles. [...]

Un taxi se detuvo, las luces de parqueo encendidas.

El chofer levantó mi equipaje con una sonrisa sarcástica:

"¡Esta vez, Shabine, como que te vas de verdad!" No le respondí al imbécil, simplemente me arrellané
En el asiento de atrás y miré al cielo incendiarse Sobre Laventille, rosado como la camisa en la que dormía

La mujer que abandona-

ba." 10

\section{El paisaje del Caribe como historia/nación}

Walcott renuncia al llamado de la Musa de la historia: confronta la épica sed de ruinas materiales que detentan otros poetas caribeños: no hay monumentos ni documentos que hablen desde la Historia del Nuevo Mundo. Todo se lo ha tragado el mar, ambivalente, que a la vez, brinda la ocasión de recomenzar. Leemos en El reino del caimito:

¿Dónde están sus monumentos, sus batallas, sus mártires?

¿Dónde su memoria tribal? Señores,

En esa bóveda gris. El mar. El mar

Los ha aprisionado. El mar es la Historia. (p. 68).11

10 "Out in the yard turning gray in the dawn, I stood like a stone and nothing else move But the cold sea rippling like galvanize And the nail holes of stars in the sky roof, Till a wind start to interfere with the trees [...] A route taxi pull up, park-lights still on. The driver size up my bags with a grin: "This time, Shabine, like you really gone!." I ain't answer the ass, I simply pile in The back seat and watch the sky burn Above Laventille pink as the gow In wich the woman I left was sleeping."

11 "Where are your monuments, your battles, martyrs? Where is your tribal memory? Sirs, In that gray vault. The sea. The sea has locked them up. The sea is History." 
Frente a la pregunta identitaria, el poeta responde más adelan-te: "Ahora no tenía más país que la imaginación.” (p. 24). En efecto, el Caribe re-escri-be la historia imperial, desde la reconciliación del sujeto y el mundo que proporciona la poíesis: la creación poética ex-presa en imágenes de lugar la respuesta resiliente del Atlánti-co negro, de ese hombre resis-tente a la alienación de la trata y de la machina- plantación en el Caribe. Así convierte el concepto de nación en una dimensión interior, en una instancia individual-colectiva, que es susceptible de analizar desde el concepto de sujeto cultural del que habla Edmond Cros (p. 97). Gracias a la dimensión individual-colectiva que inserta el sujeto cultural caribe, la nación es el hogar, macrouniverso que representa intensivamente los lazos solidarios de la organización gentilicia. Así, asistimos en El reino del caimito a la declaración identitaria del homo caribbeans:

No soy más que un negro pelirrojo enamorado del mar,

Recibí una sólida educación colonial,
De holandés, de negro y de inglés hay en mí,

De modo que no soy nadie o soy una nación. (p. 14).12

\section{El paisaje Caribe como iden-} tidad transnacional

El navío, suerte de sistema en movimiento, vivo, microcultu-ral y micropolítico, es impor-tante por razones históricas y teóricas. La nave nos remite de inmediato a travesías, a anti-guos nostos y a la circulación de ideas y agentes que funcionan como llave cultural. El barco a vela (Gilroy, 1992),13 cronotopo (Bachtín, 1989) de la ruta media 14 de la trata esclavista en el Caribe, es resultado del supersincretismo de diversas tradiciones de los Pueblos del mar (Benítez Rojo, 1989): Simbad, Sinoé, Ulises... Su significación tiene un doble valor semántico: por una parte es la nave colonizadora de la apoikía, es el Mediterráneo afroeuropeo, es la ruta de la seda y del incienso, es la balsa que permite a Odi-seo abandonar la isla de Calipso e iniciar el camino a Ítaca, el schooner Flight en el que Shabine (Walcott, 1996) inicia sus aventuras; por otra, es el barco negrero, el remo de Caronte hundiéndose en el río infernal.15

\section{El paisaje del Caribe como baluarte cimarrón}

Frente a todos los rostros de la muerte que autorizó la tragedia histórica de la esclavitud, la perpetuada alienación colonial, la pobreza y el olvido, el Caribe opone su paisaje como innegable dimensión eufórica de la vida. Dice en La voz del crepúsculo:

Froude tenía la convicción de que puesto que la historia se basaba en el logro, y que puesto que la historia de las Antillas era tan genéticamente corrupta, tan deprimente en sus ciclos de matanzas, esclavitud y trabajos forzados, era inconcebible que allí surgiera una cultura y nada podría crearse jamás en aquellos puertos destartalados, en aquellas plantaciones de azúcar feudales. Esto era negado no solo por la luz y por la sal de las montañas antillanas, sino también por la energía popular y la diversidad de sus gentes. (pp. 99-100).

En una revisión de la historia oficial, Walcott abre la puerta de la imaginación (cross-cultural

\footnotetext{
12 "I'm just a red Níger who love the sea, I had a sound colonial educarion,cto, I hace Dutch, nigger, and English in me, And either I'm nobody, or I'm a nation."

${ }_{13}$ The sailing ship.

14 Middle passage.

15 El remo es imagen metonímica del viaje como comienzo expansivo, como aventura vital, pero también representa esa pequeña muerte del exilio del hogar-patria.
} 
imagination) y se reencuentra con la memoria cultural afroantillana. En ese mismo orden de ideas, Wilson Harris (1983), había invitado a explorar deba-jo de la superficie histórica del Caribe, para descubrir el imperativo imaginativo signado por la creolización, la hibridación y la catálisis.16Afirma Walcott en El reino del caimito: "Yo que no tengo más armas que la poesía, las lanzas de las palmas y el brillante escudo del mar." (p. 47).17

En el mismo poemario, la historia patria es reemplazada por una nueva cosmogonía en el Caribe, como leemos más adelante, atada a la ingente y cándida fuerza del paisaje más que a la oscura anécdota de los hombres. De este modo, el paisaje del Caribe contesta la historia:

$\mathrm{Y}$ en la risita salada de las rocas

Con sus charcos marinos, fue el sonido

Como un rumor sin eco

alguno

De la historia, empezando

realmente. (p. 76).18
Por otra parte, Walcott postula la concepción del paisaje como entidad no domesticada, que se opone a la idea de "progreso" como modernidad tecnológica sin modernización de las mentalidades, con la consecuen-te subversión del ideologema ilustrado "civilización - barbarie." ${ }_{19}$ De este modo, desarma el complejo de Próspero, así como la pretendida missión civilisatrice del discurso imperial.

La estasis del paisaje, suerte de quietud meditativa en la que germina el sentimiento de pertenencia, se opone a la movilidad alexitímica del viajero, al ojo ligero del turista. El verdadero progreso, entonces, será el paisaje rústico, no vigilado, no codificado, una entidad que se alzará como dimensión no colonizada de la vida en el Caribe. Leemos en El reino del caimito:

[...] Luego, cuando aquel océano

De negro humo se disipó y el cielo se hizo blanco, No hubo más que Progreso, si Progreso es una iguana tan quieta como una hoja joven a la luz del sol. (p. 43).20

Así, la velocidad, inherente a la concepción occidental y tecnológica de progreso, es parte de la machina de la alienación colonial; permanecer en el siglo XIX, como los caballos antillanos, dice Walcott en La voz del crepúsculo (p. 43), quizás no sea completamente descabella-do: hay un tempo lento, decimonónico en el Caribe.

\section{Paisaje del Caribe como ar- chipiélago: ¿solitario o solida-rio?}

Así como el territorio del archipiélago 21 es un fragmento desgajado del continente, del mismo modo, la historia del archipiélago se desprende del mito, fuente poiética a la que es grato e inevitable retornar. "El arte antillano es la restaura-ción de nuestras historias rotas, nuestros fragmentos de vocabulario, y nuestro archipiélago se convierte en sinónimo de fragmentos desgajados de su conti-

\footnotetext{
${ }_{16} \quad$ La catálisis es un proceso de erosión psíquica por el cual cada grupo racial califica y disminuye la autoimagen del

17 otro. "I who have no weapon but poetry and

the lances of palms and the sea's shining shield."

${ }_{18}$ "and in the SALT chuckle of Rocks

With their sea pools, there was the sound

Like a rumor without any echo

Of History, really beginning.»

19 Como en el caso del colombiano Candelario Obeso. Ver. "El montaraz", en Cantos populares de mi

20 tierra. "Then, when that ocean

of Black smoke pass, and the sky turn white, there was nothing but progress, if progress is an iguana as still as a young leaf in sunlight."

21 Ver concepto de metarchipiélago de Benítez Rojo, un archipiélago sin centro ni límites.
} 
nente original" (Walcott, 2000, p. 92).

Esta genealogía reconstruible, este retorno a la fuente o arché, atenúa la insulada sensación de ser solo, la perpetuada sed de horizonte, siempre prospectiva, como cuando a lo lejos, en el mediodía martiniqueño, se advierte la presencia solidaria de la isla de Dominica. Por otra parte, el proceso de la creación poética, sin duda, implica una recreación a partir de la memoria fragmentada, transculturada, que enfrenta su dialecto -más bien idiolecto- a la lengua imperial.

\section{El paisaje del Caribe como naufragio}

Cuando naufraga Crusoe o la tripulación de La tempestad, el es Viejo Mundo el que naufraga (Walcott, 2000). Frente a esta pérdida, muchos escritores del Archipiélago han sentido "una nostalgia oceánica de la cultura antigua, así como una melancolía de la nueva", hasta el punto de "caer en el rechazo del paisaje sin domesticar, en un anhelo de ruinas." (Walcott, 2000, pp. 58-60).

Frente al horror vacui del mundo antiguo, el minimalismo de unas palmas espetadas contra el cielo, el sonido limpio de las olas, la explosión de la me-moria en el acto, las naves de la imaginación transhistórica escribiendo en la marea nue-va, el silencio murmurador de las calles antillanas, el reclamo del tambor como un conjuro en los pies. Los sobrevivientes del naufragio hemos recomenzado la historia con nuestro propio signo. El Caribe sería, pues, un terreno palimpsestuoso, en donde es imposible e infructuoso tratar de hallar el texto original, pero en el cual es legible cier-ta intertextualidad cultural $\mathrm{y}$ lingüística. Michael Dash relaciona la idea bajtiniana de dia$\operatorname{logismo}_{22}$ con la definición de creolización, no como un proceso de homogenización sino de contienda creativa e interac-ción (Dash, 1998). Así, deshe-chada la idea de comienzo trascendental, cobra importancia la noción de flujo y constante movimiento.

\section{La poética de la relación de Edouard Glissant 23}

En Edouard Glissant, el paisaje caribeño es concebido en contraste con el catalogado, monolingüe y monócromo mundo europeo. El paisaje del Nuevo Mundo ofrece a la imaginación una suerte de metalenguaje en el cual se puede rescribir la historia en una nueva gramática de sentimientos y sensaciones. El rol del paisaje es cardinal en el discurso caribeño: supera su categoría de décor consentant, de entorno balsámico y emerge como una auténtica energía que impulsa al hombre a sumergirse dentro de él y re-conocerse. (Glissant, 1981).

Por otra parte, la involución de las islas caribeñas obedece a un balance histórico negativo ocasionado por las reiteradas oportunidades perdidas, situación que da lugar a lo que Glissant llama no historia caribeña, debido, por una parte, a la ausencia de memoria colectiva y a la perpetuación del sofisma de la esperanza 24 en relación con la situación colonial. La histo-ria caribeña está signada por la sincronía transcultural de los procesos creolizadores, frente a la diacronía de la Historia europea, cuya fuerte dimensión cronológica y cuyo impulso totalizador contrasta con el tiempo circular, fragmentado y diverso de las islas. La amnesia histórica del Caribe es producto de una superposición de sucesivos "paisajes" identitarios: el paraíso terrenal (locus amoenus), la illusio de una africanía 25 mítica

22 El dialogismo designa en Bajtín la alternancia de voces en la polifonía textual.

23 Ver Le Discours Antillais (Éditions du Seuil, 1981) y Poétique de la Relation (Gallimard, 1991).

24 Dentro de las falacias retóricas, la apelación a los sentimientos ocupa un gran capítulo y, entre ellas, la invocación a la espe-ranza tiene un lugar central. Consiste en argumentar con total convicción una solución vaga e improbable en el futuro, para los acuciantes y puntuales problemas del presente.

25 Sierra Díaz, D.C. (julio-diciembre de 2016). El Muntu: la diáspora del pensamiento filosófico africano en Changó, el gran putas de Manuel Zapata Olivella. La Palabra, (29), 23-44 
$a b$ origine y el espejismo de la identidad metropolitana. Para Glissant, escribir la verdadera historia del Caribe es tarea de poetas y narradores, dado que la intención poética sustituye a la intención histórica.26

En el Caribe, las fronteras nacionales dividen políticamente las naciones culturales: los procesos coloniales fraccionan en territorios franceses, ingleses, holandeses y españoles, una región cuya población es mayoritariamente africana. La experiencia de la soledad insular se combina con la experiencia de la solidaridad regional en el metarchipiélago del Caribe, la "Otra América". Ese viaje desde un mundo cerrado -la isla, la plantación- es un tópico recurrente en las literaturas y el arte caribeños, y se materializa en las imágenes de la nave, de la espiral y del camino que se repite. Glissant define la literatura nacional como la urgencia de cada comunidad de autoafirmarse a sí misma, la necesidad de no borrarse del mundo, por el contrario, la satisfacción de compartir respetando su diferencia.

El tiempo en el Caribe es concebido como un flujo en donde discurre la memoria colectiva: es estructuralmente épico, vale decir, estructurado sobre el principio aditivo. Pero su decurso no es lineal ni armonioso: procede por golpes polifónicos.
Edouard Glissant ve el tiempo en el espacio como duración, en donde pasado y futuro están enlazados. Así, la poética transcultural del continente americano se caracteriza por la ansiosa y caótica búsqueda de duración temporal, mientras que la poética del continente europeo, por la inspiración y la súbita irrupción del momento singular. La poética caribeña es en Glissant, también una poética de la exuberancia y del éxtasis, salida poética para el náufrago. El Caribe se expresa a través de un arte crudo, sin pulir, que no se rinde a la subjetividad del autor, sino que expresa las pulsiones del inconsciente colectivo, en su flujo inédito y anómico. La oscura carnalidad verbal del Caribe se opone a la clara esté-tica desencarnada de la cultura hegemónica.

\section{Conclusión}

En tanto representación, el paisaje es portador de una visión de mundo, de un habitus (Bourdieu, 1995). En tal sentido, la poesía del caribe ha construido nuevas formas de inscripción de la significación. En la poesía de Derek Walcott, el paisaje es protagonista, no marco decorativo: se instaura como polo dialógico en contrapunto con el cual el poeta construye su apuesta artística. En su máqui-na poética, el paisaje es fuerza centrípeta y centrífuga a la vez: vuelve al mundo antiguo para reconocerse y distanciarse, pero también manifiesta una nueva pulsión de vida que edifica un mundo nuevo. En la tesis desmitificadora de Le discours antillais, Edouard Glissant aporta novedosos conceptos, como el de mismidad/ diversidad, imaginación transcultural, poética natural, entre los que se destaca la fuerza estructuradora del paisaje, la comunidad y el inconsciente colectivo, los conceptos de sujeto descentrado, latencia, opacidad, metamorfosis, flujo, poética de la relación, happy zombie, entre otros. De este modo, las poéticas del paisaje caribe se convierten en ruta de memorias supersincréticas -eco diferente y diferido de Europa, Asia y África- pero, a la vez, en insustituible cimiento de la comunidad imaginada de la nación créole.

\section{Agradecimientos}

Agradezco la gentil y generosa invitación de la Université des Antilles et de la Guyane y, en especial, a Raphaël CONFIANT, Philippe JOSEPH y Jean-Ma-rie FOTSING, organizadores y coordinadores del Colloque international et pluridisciplinai-re, Paysages et biodiversités de la Caraïbe et des Guyanes De la connaissance et de la représentation des paysages à leur aménagement durable, magnífico encuentro que tuvo lugar en Martinica, en diciembre de 2010.

26 La imaginación debe desenterrar verdades no oficiales que la historia oficial ha suprimido (Glissant, 2008, pp. 37-38). 


\section{Referencias}

Ashcroft, B., Griffiths, G., \& Tiffin, H. (1989). The Empire Writes Back. London and New York: Rout-ledge.

Benítez Rojo, A. (1992). The Repeating Island, The Caribbean and the Posmodern Perspective. Durham and Londres: Duke University Press.

Cros, E. (1997). El sujeto Cultural. Sociocrítica y psicoanálisis. Buenos Aires: Ediciones Corregidor.

Dash, M. (1998). The Other America. Caribbean Litterature in a New World Context. New World Studies. Charlottesville and London: University Press of Virginia.

Gilroy, P. (1992). Black Atlantic: Modernity and Double Consciousness. Cambridge: Harvard, UP.

Glissant, E. (2008). Le Discours Antillais. Paris: Éditions Gallimard.

Maglia, G. (2010). Si yo fuera tambó: Candelario Obeso y Jorge Artel: Poesía selecta. Bogotá: Editorial Javeriana y Editorial Universidad del Rosario

Maglia, G. (2009). De la machina imperial a la vereda tropical. Poesía, identidad y nación en el caribe afrohispánico. Bogotá: Editorial Javeriana.

Montenegro de la Hoz, N. (2014). Changó, el gran putas: formas de resistencia e identidad esclavizada en los estudios poscoloniales. La Palabra, (24), 59-66

Sierra Díaz, D.C. (j2016). El Muntu: la diáspora del pensamiento filosófico africano en Chan-gó, el gran putas de Manuel Zapata Olivella. La Palabra, (29), 23-44. doi: http://dx.doi. org/10.19053/01218530.n29.2016.5699

Walcott, D. (1996). El reino del caimito. Bogotá: Editorial Norma.

Walcott, D. (2000). La voz del crepúsculo. Madrid: Alianza Editorial.

Walcott, D. (2005). La Odisea, The Odyssey. Madrid: Visor Libros. 